\title{
PERENCANAAN ANGKUTAN SEKOLAH GUNA MEWUJUDKAN KONSEP RASS (RUTE AMAN SELAMAT SEKOLAH) DI KOTA TANJUNG SELOR
}

\author{
Febria Suci Ulandari \\ Taruna Program Diploma IV \\ Transportasi Darat \\ Sekolah Tinggi Transportasi Darat \\ Jl. Raya Setu KM. 3,5 Cibuntu \\ Cibitung Bekasi \\ Tlp: (021) 8254640 \\ Fax: (021) 82608995 \\ febriasuciul@gmail.com
}

\author{
Dr. Efendhi Prih R, MT \\ Dosen Program Diploma IV \\ Transportasi Darat \\ Sekolah Tinggi Transportasi \\ Darat Jl. Raya Setu KM. 3,5 \\ Cibuntu Cibitung Bekasi \\ Tlp: (021) 8254640 \\ Fax: (021) 82608995
}

\author{
Ir. Juliaman Pangaribuan, MSi \\ Dosen Program Diploma IV \\ Trasnportasi Darat \\ Sekolah Tinggi Transportasi Darat \\ Jl. Raya Setu KM. 3,5 Cibuntu \\ Cibitung Bekasi \\ Tlp: (021) 8254640 \\ Fax: (021) 82608995
}

\begin{abstract}
School transportation is a shuttle service to transport students. This study aims to review the school transportation system planning through efficient route planning, effective and fair manner and determine the operational standards of school transport services based on preferences of potential users. This research was conducted in six locations: SDN 01 TJS, SDN 07 TJS, SMPN 01 TJS, SMAN 01 TJS, SMKN 01 TJS, SMKN 02 TJS.

The data collected through the survey is needed in the field of primary and secondary survey to the relevant government agencies. Analysis is conducted to know the number of actual demand and moderate, routes, fleet types and quantities, transport services, vehicle operating costs and subsidies.

The results showed that school transportation service is made in two alternative plans for the kind of used bus fleet with a capacity of 20 people. For the first demand actual fleet size 2, 5 potential demand, actual demand for the service fleet number 3 , the potential demand 9. For the subsidy to be paid by the government in one day $R p$ 1,671,621.82 actual demand and moderate demand Rp5.682.559,47.
\end{abstract}

Key words: actual demand and moderate demand, route, type of fleet, servicing, subsidies.

\begin{abstract}
ABSTRAK
Angkutan sekolah merupakan pelayanan untuk mengantar jemput siswa sekolah. Penelitian ini bertujuan untuk meninjau perencanaan sistem transportasi sekolah melalui perencanaan rute efisien, efektif dan cara yang adil dan menentukan standar operasional layanan transportasi sekolah berdasarkan preferensi calon pengguna. Penelitian ini dilakukan di 6 lokasi yaitu SDN 01 TJS, SDN 07 TJS, SMPN 01 TJS, SMAN 01 TJS, SMKN 01 TJS, SMKN 02 TJS.

Data yang dikumpulkan melalui survey yang diperlukan di bidang survey primer dan sekunder ke instansi pemerintah terkait. Analisis yang dilakukan adalah mengetahui jumlah permintaan actual dan moderat, rute, jenis armada dan jumlah, pelayanan angkutan, biaya operasi kendaraan serta subsidi.

Hasil penelitian menunjukan bahwa rute angkutan sekolah dibuat dalam dua rencana alternative untuk jenis armada bus yang digunakan dengan kapasitas 20 orang. Untuk rute 1 demand actual jumlah armada 2, demand potensial 5, untuk rute demand actual jumlah armada 3, demand potensial 9. Untuk subsidi yang harus dibayarkan pemerintah dalam satu hari demand actual Rp 1.671.621,82 dan demand moderat Rp5.682.559,47
\end{abstract}

Kata Kunci : Permintaan actual dan permintaan moderat, rute, jenis armada, pelayanan, subsidi. 


\section{PENDAHULUAN}

\section{Latar Belakang}

Berdasarkan data kecelakaan yang ada menunjukkan bahwa tingkat kecelakaan di Kota Tanjung Selor tertinggi terdapat pada umur 11 tahun sampai 20 tahun yaitu sebesar 32\% dari total kejadian kecelakaan yang terjadi. Saat ini baik anak SD, SMP, maupun SMA tidak memiliki pilihan untuk melakukan pergerakan menuju sekolah. . Kondisi ini juga didukung dengan pelayanan angkutan umum yang belum sesuai dengan harapan pelajar. Angkutan umum dengan tingkat kepastian, keamanan, dan kenyamanan yang cukup baik masih belum tersedia untuk menunjang kegiatan para pelajar.

Di Kota Tanjung Selor ini, banyak orang tua meyakini bahwa sepeda motor adalah solusi ke sekolah agar cepat dan murah. Fenomena sepeda motor inilah yang sering berakibat buruk terhadap keselamatan jalan. Berdasarkan uraian diatas maka peneliti tertarik untuk melakukan suatu penelitian dengan wujud kepedulian atas lokasi sekolah yang kurang ramah untuk diakses murid dengan angkutan sekolah itulah yang mendorong inisiatif untuk menyediakan sarana yang aman dan selamat bagi pelajar.

\section{Tujuan}

Adapun tujuan penelitian ini adalah :

a. Menghitung permintaan kebutuhan pelayanan angkutan sekolah;

b. Menentukan pelayanan rute ideal untuk pengoperasian angkutan sekolah;

c. Menghitungkan kebutuhan armada

d. Menghitung tarif yang harus dikeluarkan untuk penggunaan angkutan sekolah.

e. Menentukan jenis armada yang cocok untuk pengoperasian angkutan sekolah; 


\section{PEMBAHASAN}

\section{Pengumpulan Data}

Data yang dikumpulkan dalam penelitiaan ini terbagi menjadi 2 jenis data, yaitu :

\begin{tabular}{|c|c|c|c|}
\hline DATA & SUMBER DATA & KEGUNAAN DATA & $\begin{array}{l}\text { JENIS } \\
\text { DATA }\end{array}$ \\
\hline PETA TATA GUNALAHAN & BAPPEDA & $\begin{array}{l}\text { UNTUK MENGETAHUI TATA GUNA LAHAN DI WILAYAH } \\
\text { STUDI }\end{array}$ & \multirow{4}{*}{$\begin{array}{l}\text { DATA } \\
\text { SEKUNDER }\end{array}$} \\
\hline PETA JARINGAN JALAN & $\begin{array}{l}\text { DINAS PU KOTA } \\
\text { TANJUNG SELOR }\end{array}$ & UNTUK MENGETAHUI FUNGSI JALAN & \\
\hline PETA JARINGAN TRAYEK & $\begin{array}{l}\text { TIM PKL KOTA } \\
\text { TANJUNG SELOR }\end{array}$ & $\begin{array}{l}\text { UNTUK MENGETAHUI PELAYANAN ANGKUTAN UMUM } \\
\text { DI KOTA TANJUNG SELOR }\end{array}$ & \\
\hline DATA INVENTARISASI SEKOLAH & $\begin{array}{l}\text { DINAS } \\
\text { PENDIDIKAN } \\
\text { KOTA TANJUNG } \\
\text { SELOR } \\
\end{array}$ & $\begin{array}{l}\text { UNTUK MENGET AHUI JUMLAH SEKOLAHYANG ADA DI } \\
\text { WILAYAH STUDI SERTA JUMLAH PELAJAR TIAP } \\
\text { SEKOLAH }\end{array}$ & \\
\hline $\begin{array}{l}\text { DATA KARAKTERISTIK PELAJAR } \\
\text { 1. JENIS KELAMIN }\end{array}$ & \multirow{8}{*}{$\begin{array}{l}\text { SURVEI } \\
\text { WAWANCARA } \\
\text { PELAJAR }\end{array}$} & $\begin{array}{l}\text { 1. UNTUK MENGETAHUI PROSENTASE LAKI-LAKI ATAU } \\
\text { PEREMPUAN }\end{array}$ & \multirow{8}{*}{$\begin{array}{l}\text { DATA } \\
\text { PRIMER }\end{array}$} \\
\hline 2. ASAL TUJUAN PELAJAR & & 2. UNTUK MENGETAHUI POLA PERGERAKAN PELAJAR & \\
\hline $\begin{array}{l}\text { 3. MODA YANG DIGUNAKAN } \\
\text { PELAAAR SERTA ALASAN } \\
\text { PEMTLIHANMODAYYNG } \\
\text { DIGUNAKAN }\end{array}$ & & $\begin{array}{l}\text { 3. UNTUK MENGETAHUI PROSENTASE PENGGUNAAN } \\
\text { MODA YANG DIGUNAKAN PELANAR }\end{array}$ & \\
\hline $\begin{array}{l}\text { 4. BIAYA YANG DIKELUARKAN } \\
\text { SEHARI-HARI MENUUUSEKOLAH }\end{array}$ & & $\begin{array}{l}\text { 4. UNTUK MENGETAHUI PROSENTASE BIAYA YANG } \\
\text { DIKELUARKAN PELAJAR }\end{array}$ & \\
\hline $\begin{array}{l}\text { 5. PENILAIAN TERHADAP } \\
\text { PELAYANAN ANGKUTANUMUM }\end{array}$ & & 5. UNTUK MENGETAHUI KONDISI ANGKUTAN UMUMM & \\
\hline $\begin{array}{l}\text { 6. TANGGAPAN TERHADAP } \\
\text { ANGKUTAN SEKOLAH }\end{array}$ & & $\begin{array}{l}\text { 6. UNTUK MENGETAHUI SERERAPA BESAR PELAUAR } \\
\text { YANG SETUJUTERHADAP ADANYA ANGKUTAN } \\
\text { SEKOLAH }\end{array}$ & \\
\hline $\begin{array}{l}\text { 7. KEBERSEDIAAN PINDAH } \\
\text { MENGGUNAKAN ANGKUTAN } \\
\text { SEKOLAH }\end{array}$ & & $\begin{array}{l}\text { 7. UNTUK MENGETAHUI DEMAND TERHADAP } \\
\text { ANGKUTAN SEKOLAH }\end{array}$ & \\
\hline $\begin{array}{l}\text { 8. HARAPAN PELAUAR TERHADAP } \\
\text { ANGKUTAN SEKOLAH }\end{array}$ & & $\begin{array}{l}\text { 8. UNTUK MEMBERIKAN PELAYANANYANG SESUAI } \\
\text { DENGAN KEINGINAN PELAJAR }\end{array}$ & \\
\hline
\end{tabular}

Tabel 1 Kebutuhan Data

\section{Landasan Teori}

1. Sampel Penelitian

Pengertian sampel menurut Sugiyono (2008 : 116) adalah bagian dari jumlah dan karakteristik yang dimiliki oleh populasi tersebut, sampel yang diambil dari populasi harus betul-betul representative (mewakili).

$$
n=\frac{N}{N \cdot e^{2}+1}
$$

Rumus 1
$\mathrm{n} \quad=$ jumlah sampel menurut stratum
$\mathrm{N}=$ jumlah populasi seluruhnya
e $=$ tingkat presisi $(5 \%)$

2. Analisis Jumlah Kebutuhan Armada

Analisis ini dimaksudkan untuk keseimbangan antara penawaran jumlah kendaraan dengan permintaan sejumlah penumpang pada suatu rute tertentu.

$$
K=\frac{W O-T A B}{H \times f A}
$$

K

$$
=\text { Jumlah kendaraan (unit) }
$$




$$
\begin{array}{ll}
\mathrm{H} & =\text { Waktu antara (menit) } \\
f \mathrm{~A} & =\text { Factor ketersediaan kendaraan }(100 \%) \\
\mathrm{WO} & =\text { Waktu operasi per shift (menit) } \\
\mathrm{T} \mathrm{AB} & =\text { Waktu perjalanan rata-rata dari A ke B (menit) }
\end{array}
$$

3. Analisis Perhitungan Biaya Operasi Kendaraan

Perhitungan biaya operasi kendaraan yang digunakan adalah menurut SK.DIRJEN HUBDAT NO 687 Tahun 2002, didalam perhitungan BOK ini terdapat dua komponen biaya yang utama yaitu biaya langsung dan biaya tidak langsung. Dimana komponen - komponen yang terkait didalamnya adalah :
a. Biaya tetap (fixed cost)
b. Biaya tidak tetap (variable cost)
c. Biaya lain meliputi biaya perijinan dan administrasi (STNK, KIR, Ijin Usaha, Asuransi, dan Ijin Trayek).

4. Analisis Biaya Pokok per Penumpang (Tarif)

Biaya pokok per penumpang dihitung setelah memasukkan besarnya keuntungan (margin) yang wajar bagi operator. Besarnya keuntungan yang wajar adalah sebesar $10 \%$ dari biaya operasi yang dikeluarkan.

$$
\text { Tarif }=\frac{(\text { BOK }+(\text { BOK } \times 10 \%))}{\text { jumlah penumpang } / \text { tahun }} \quad \text {...................... Rumus } 3
$$

\section{Analisis Data}

Dalam proses ini analisis data ini, dibagi menjadi beberapa tahapan analisis, yaitu :

1. Distribusi Perjalanan Pelajar

Untuk persebaran pelajar menuju sekolah diklasifikasikan menjadi 2 bagian, yaitu internal (dalam Kota Tanjung Selor) yang terdiri dari 22 zona dan zona eksternal (luar Kota Tanjung Selor) yang terdiri dari 4 zona. Dari hasil wawancara dapat diketahui adal tujuan tertinggi zona internal yaitu zona 3 sebanyak 313 pelajar. Sedangkan untuk asal tujuan tertinggi zona eksternal yaitu zona 24 sebanyak 156 pelajar. 
2. Analisis Permintaan Penumpang Angkutan Sekolah

Tabel 2 Demand Aktual

\begin{tabular}{|c|c|c|c|}
\hline OD & 1 & 4 & TJ \\
\hline 1 & 41 & 20 & 61 \\
\hline 2 & 14 & 7 & 21 \\
\hline 3 & 53 & 22 & 75 \\
\hline 4 & 46 & 23 & 70 \\
\hline 5 & 48 & 20 & 68 \\
\hline 6 & 30 & 16 & 46 \\
\hline 7 & 22 & 8 & 29 \\
\hline 8 & 29 & 17 & 46 \\
\hline 9 & 30 & 15 & 46 \\
\hline 10 & 27 & 12 & 40 \\
\hline 11 & 14 & 8 & 22 \\
\hline 12 & 16 & 4 & 19 \\
\hline 13 & 16 & 4 & 19 \\
\hline 14 & 9 & 4 & 13 \\
\hline 15 & 9 & 4 & 13 \\
\hline 16 & 13 & 4 & 17 \\
\hline 17 & 11 & 4 & 15 \\
\hline 18 & 9 & 4 & 13 \\
\hline 19 & 11 & 2 & 13 \\
\hline 20 & 12 & 4 & 16 \\
\hline 21 & 9 & 4 & 13 \\
\hline 22 & 9 & 4 & 13 \\
\hline 23 & $\mathbf{0}$ & $\mathbf{0}$ & 0 \\
\hline 24 & 30 & 8 & $\mathbf{3 8}$ \\
\hline 25 & $\mathbf{0}$ & $\mathbf{0}$ & 0 \\
\hline 26 & 11 & 4 & 14 \\
\hline AJ & 517 & 220 & 737 \\
\hline
\end{tabular}

Tabel 3 Demand Potensial

\begin{tabular}{|c|c|c|c|}
\hline OD & 1 & 4 & TJ \\
\hline 1 & 147 & 64 & 211 \\
\hline 2 & 52 & 26 & 78 \\
\hline 3 & 181 & 71 & 252 \\
\hline 4 & 160 & 77 & 238 \\
\hline 5 & 168 & 64 & 232 \\
\hline 6 & 101 & 52 & 153 \\
\hline 7 & 72 & 26 & 98 \\
\hline 8 & 103 & 58 & 161 \\
\hline 9 & 101 & 52 & 152 \\
\hline 10 & 95 & 45 & 140 \\
\hline 11 & 42 & 26 & 68 \\
\hline 12 & 50 & 13 & 63 \\
\hline 13 & 50 & 13 & 63 \\
\hline 14 & 29 & 13 & 42 \\
\hline 15 & 29 & 13 & 42 \\
\hline 16 & 43 & 13 & 56 \\
\hline 17 & 35 & 13 & 48 \\
\hline 18 & 29 & 13 & 42 \\
\hline 19 & 36 & 6 & 43 \\
\hline 20 & 44 & 13 & 57 \\
\hline 21 & 29 & 13 & 42 \\
\hline 22 & 29 & 13 & 42 \\
\hline 23 & 0 & 0 & 0 \\
\hline 24 & 101 & 26 & 127 \\
\hline 25 & 0 & 0 & 0 \\
\hline 26 & 36 & 13 & 49 \\
\hline AJ & 1761 & 736 & 2497 \\
\hline
\end{tabular}

Untuk menentukan permintaan aktual, diasumsikan pelajar yang menggunakan angkutan umum pada kondisi eksisting dari hasil wawancara mau berpindah menggunakan angkutan sekolah jika perencanaan angkutan sekolah memberikan pelayanan yang lebih baik dibandingkan dengan angkutan umum. dapat dilihat bahwa potensi penumpang sebesar 737 pelajar dimana demand terbesar secara keseluruhan yang menuju zona 1 dan zona 4 yaitu pelajar yang berasal dari kedua zona tersebut yaitu sebesar 75 pelajar.

Sedangkan demand potensial didapat dari matriks asal tujuan pelajar pengguna angkutan umum ditambah dengan pengguna kendaraan pribadi yang bersedia pindah ke angkutan sekolah. Jumlah demand potensial adalah sebesar 2497 pelajar dimana demand terbesar secara keseluruhan yang menuju zona 1 dan zona 4 yaitu pelajar yang berasal dari kedua zona tersebut yaitu sebesar 252 pelajar.

3. Analisis Kebutuhan Kendaraan

Jumlah kebutuhan kendaraan dihitung dengan menggunakan data waktu operasi, waktu perjalanan, waktu antara (headway), factor muat.

Hasil penelitian menunjukkan untuk rute 1 yang terbesar terdapat pada demand potensial dengan jumlah kendaraan sebesar 5 unit, waktu tempuh perjalanan sebesar 30.20 menit, waktu antara 6 menit. Sama hal nya dengan rute 1, rute 2 terbesar 
terdapat pada demand potensial dengan jumlah kendaraan 9 unit, waktu tempuh perjalanan sebesar 22.14 menit, waktu antara 4 menit. Tabel dibawah menunjukkan jumlah kebutuhan kendaraan pada tiap rute.

Tabel 4 Jumlah Armada Yang Dibutuhkan

\begin{tabular}{ccc}
\hline \multirow{2}{*}{ No. Rute } & \multicolumn{2}{c}{ Kebutuhan Armada } \\
& Aktual & Potensial \\
\hline AS I & 2 & 5 \\
AS II & 3 & 9 \\
\hline Total & 5 & 14 \\
\hline
\end{tabular}

4. Analisis BOK \& Tarif

Tabel 5 Rekapitulasi Biaya Operasi Kendaraan Angkutan Sekolah

\begin{tabular}{|c|c|c|c|c|c|}
\hline \multirow{2}{*}{ No } & \multirow{2}{*}{ Rekapitulasi Biaya per Km } & \multicolumn{2}{|c|}{ RUTE AS 1} & \multicolumn{2}{|c|}{ RUTE AS 2} \\
\hline & & AKTUAL & POTENSIAL & AKTUAL & POTENSIAL \\
\hline \multirow[t]{16}{*}{1} & Biaya Langsung & & & & \\
\hline & Penyusutan & Rp3,496.36 & $\mathrm{Rp} 3,496.36$ & $\mathrm{Rp} 3,789.30$ & Rp3,789.30 \\
\hline & Bunga modal & Rp786.68 & Rp786.68 & Rp852.59 & Rp852.59 \\
\hline & Gaji dan tunjangan awak bus & $\mathrm{Rp} 2,444.49$ & $\mathrm{Rp} 2,444.49$ & $\mathrm{Rp} 2,649.30$ & Rp2,649.30 \\
\hline & BBM & Rp822.22 & Rp822.22 & Rp822.22 & Rp822.22 \\
\hline & Ban & Rp81.20 & Rp81.20 & Rp81.20 & Rp81.20 \\
\hline & Service kecil & Rp102.50 & Rp102.50 & Rp102.50 & Rp102.50 \\
\hline & Service besar & Rp54.58 & Rp54.58 & Rp54.58 & Rp54.58 \\
\hline & Over Houl mesin & Rp131.11 & Rp131.11 & Rp131.11 & Rp131.11 \\
\hline & Over Houl body & Rp254.63 & $\mathrm{Rp} 254.63$ & Rp275.97 & Rp275.97 \\
\hline & Retribusi terminal & Rp50.93 & Rp50.93 & Rp55.19 & Rp55.19 \\
\hline & STNK/pajak kendaraan & Rp109.26 & Rp109.26 & Rp118.42 & Rp118.42 \\
\hline & Kir & Rp9.26 & Rp9.26 & Rp10.04 & Rp10.04 \\
\hline & cuci bis & $\mathrm{Rp} 1,018.54$ & Rp1,018.54 & $\mathrm{Rp} 1,103.87$ & $\mathrm{Rp} 1,103.87$ \\
\hline & Asuransi & Rp32.78 & Rp32.78 & Rp35.52 & Rp35.52 \\
\hline & Total Biaya Langsung & Rp9,394.55 & Rp9,394.55 & Rp10,081.82 & Rp10,081.82 \\
\hline \multirow[t]{3}{*}{2} & Biaya Tidak Langsung & & & & \\
\hline & Biaya Gaji Pegawai non awak bus & & & & \\
\hline & Biaya Pengelolaan & Rp6.94 & Rp2.78 & Rp5.02 & Rp1.67 \\
\hline 3 & Biaya pokok/bus-km & $\mathrm{Rp} 9,401.49$ & Rp9,397.32 & Rp10,086.84 & Rp10,083.49 \\
\hline
\end{tabular}




\begin{tabular}{|c|c|c|c|c|c|}
\hline \multirow{2}{*}{ No } & \multirow{2}{*}{ Rekapitulasi Biaya per $\mathbf{K m}$} & \multicolumn{2}{|c|}{ RUTE AS 1} & \multicolumn{2}{|c|}{ RUTE AS 2} \\
\hline & & AKTUAL & POTENSIAL & AKTUAL & POTENSIAL \\
\hline 4 & Tarif Pokok & Rp470.07 & Rp469.87 & Rp504.34 & Rp504.17 \\
\hline 5 & $\begin{array}{l}\text { Tarif Yang dikenakan Untuk tarif } \\
\text { flat }\end{array}$ & $\mathrm{Rp} 4,731.77$ & $\mathrm{Rp} 4,729.67$ & Rp3,722.044 & Rp3,720.809 \\
\hline 6 & Tarif/pnp dibulatkan & $\mathrm{Rp} 4,800.00$ & $\mathrm{Rp} 4,800.00$ & $\mathrm{Rp} 3,800.00$ & Rp3,800.00 \\
\hline
\end{tabular}

Tabel 5 menunjukkan tarif yang dikenakkan kepada pengguna angkutan sekolah sebesar Rp4.800,00 untuk rute 1 dan Rp3.800 untuk rute 2.

5. Analisis Subsidi

Dari perhitungan biaya operasi kendaraan dan hasil perhitungan tarif diketahui bahwa tarif yang diberlakukan cukup tinggi mengingat konsumen dari angkutan ini adalah pelajar. Mengingat angkutan yang direncanakan ini merupakan angkutan khusus pelajar, maka direncanakan dalam menetapkan tarif baru harus dibawah dari tarif angkutan umum yang ada, dimana tarif angkutan umum di Kota Tanjung Selor untuk umum tidak tetap, yaitu berkisar Rpp7.000,00 - Rp20.000,00, namun tarif bagi pelajar sebesar Rp5.000,00. Dari peraturan tersebut maka ditetapkan tarif angkutan sekolah bersubsidi adalah Rp2.000,00.

Adapun besarnya subsidi per hari yang harus dikeluarkan pemerintah untuk penerapan tarif sebagian subsidi pada masing-masing rute dan masing-masing jenis permintaan angkutan sekolah dapat dilihat pada tabel berikut ini :

Tabel 6 Subsidi per Hari untuk Angkutan Sekolah

\begin{tabular}{cccccc}
\hline \multirow{2}{*}{ No. Rute } & $\begin{array}{c}\text { Tarif yang } \\
\text { Ditetapkan (Rp) }\end{array}$ & \multicolumn{2}{c}{ Jumlah Permintaan } & \multicolumn{2}{c}{ Subsidi per Hari (Rp) } \\
& & Aktual & Potensial & Aktual & Potensial \\
\hline AS I & $2,000.00$ & 315 & 1062 & $860,027.87$ & $2,899,102.42$ \\
AS II & $2,000.00$ & 471 & 1618 & $811,593.95$ & $2,783,457.05$ \\
\hline
\end{tabular}

Subsidi yang diperlukan dapat dihitung melalui tarif yang didapatkan dari Biaya Operasi Kendaraan dikurangi dengan tarif yang akan ditentukan dan dikalikan dengan demand yang ada. Subsidi tersebut merupakan subsidi dalam satu hari operasi yang harus dikeluarkan oleh Pemerintah Daerah untuk keseluruhan penumpang. 


\section{KESIMPULAN}

1. Dari hasil survei wawancara pelajar diketahui pergerakan yang ditimbulkan oleh pelajar, perjalanan pelajar terbesar adalah pelajar yang berasal dari zona 3 dengan jumlah sampel sebesar 36 pelajar atau jumlah populasi sebanyak 313 pelajar. Dimana tata guna lahan zona 3 di dominasi oleh kawasan pemukiman.

2. Berdasarkan hasil survei wawancara, diketahui bahwa jumlah permintaan untuk angkutan sekolah adalah 737 pelajar untuk permintaan aktual dan 2497 pelajar untuk permintaan potensial.

3. Terdapat dua rute rencana pengoperasian angkutan sekolah di Kota Tanjung Selor yaitu rute AS 1 dengan panjang rute $10.066 \mathrm{~km}$ dan rute AS 2 dengan panjang rute $7.379 \mathrm{~km}$.

4. Jumlah kendaraan yang dibutuhkan pada berjumlah 5 unit pada demand actual dan 14 unit pada demand potensial.

5. Besar tarif yang tepat untuk diterapkan dalam rencana pengoperasian angkutan sekolah di Kota Tanjung Selor disesuaikan dengan Peraturan Bupati Kabupaten Bulungan yaitu sebesar Rp2.000,00. Adapun besaran subsidi yang harus dikeluarkan untuk menutup selisih harga antara BOK dengan tarif yang akan berlaku per harinya yaitu rata-rata Rp1.671.621.82 untuk jenis permintaan aktual dan Rp5.682.559.47 untuk jenis permintaan potensial.

\section{DAFTAR PUSTAKA}

1 .

(2009) Undang-undang Nomor 22 Tahun 2009 Tentang Lalu

Lintas dan Angkutan Jalan, Direktorat Jenderal Perhubungan Darat, Jakarta

2.

(2003) Keputusan Mentri Perhubungan Nomor 35 Tahun 2003

Tentang Penyelenggaraan Angkutan Orang di Jalan dengan Kendaraan Umum, Direktorat Jenderal Perhubungan Darat, Jakarta

3.

(2002) Surat Keputusan Direktur Jendral Perhubungan Darat Nomor 687 Tahun 2002 Tentang Penyelenggaraan Angkutan Penumpang Umum di Wilayah Perkotaan Dalam Trayek Tetap dan Teratur, Direktorat Jendral Perhubungan Darat, Jakarta

4.

(2007) Peraturan Direktur Jenderal Perhubungan Darat Nomor 967 Tahun 2007 Tentang Pedoman Teknis Penyelenggaraan Angkutan Sekolah. 
5. (1996) Keputusan Direktur Jenderal Perhubungan Darat Nomor 271 Tahun 1996 Tentang Pedoman Teknis Perekayasaan Tempat Pemberhentian Kendaraan Penumpang umum.

6. Anasrul, Fajar (2012) Analisis Financial Rencana Pengoperasian Angkutan Sekolah Malang International Education Park Di Kota Malang, UNS, Solo

7. Budiman, Amin (2009) Konsep Struktur Kota \& Persebaran Fasilitas Pendidikan Dalam Penentuan Rute Angkutan Sekolah Di Kota Banda Aceh, UNDIP, Semarang

8. Irfan, Muhammad (2013) Rencana Pengoperasian Bis Sekolah Di Kota Semarang, UNDIP, Semarang

9. Kelompok PKL Kota Tanjung Selor (2014) Pola Umum Transportasi Darat Kota Tanjung Selor, STTD, Bekasi

10. Tamin, O.Z. (2008) Perencanaan, Permodelan, dan Rekayasa Transportasi, Bandung

11. Wicaksono, Ahmad (2009) Studi Identifikasi Kebutuhan Angkutan Sekolah Dasar Di Kecamatan Klojen Kota Malang, UNBRAW, Malang 